\title{
Cholesterol metabolism in aging simultaneously altered in liver and
} nervous system

\author{
Valéria Sutti Nunes ${ }^{1}$, Guilherme da Silva Ferreira ${ }^{1}$, Eder Carlos Rocha Quintão ${ }^{1}$ \\ ${ }^{1}$ Laboratorio de Lipides (LIM10), Hospital das Clinicas HCFMUSP, Faculdade de Medicina, Universidade de Sao \\ Paulo, Sao Paulo, Bazil
}

Correspondence to: Valéria Sutti Nunes; email: valeria.sutti@hc.fm.usp.br

Keywords: cholesterol, 24-hydroxycholesterol, aging, liver, brain

Received: September 15, 2021 Accepted: December 8, 2021

Published: February 7, 2022

Copyright: (c) 2022 Nunes et al. This is an open access article distributed under the terms of the Creative Commons Attribution License (CC BY 3.0), which permits unrestricted use, distribution, and reproduction in any medium, provided the original author and source are credited.

\section{ABSTRACT}

In humans, aging, triggers increased plasma concentrations of triglycerides, cholesterol, low-density lipoproteins and lower capacity of high-density lipoproteins to remove cellular cholesterol. Studies in rodents showed that aging led to cholesterol accumulation in the liver and decrease in the brain with reduced cholesterol synthesis and increased levels of cholesterol 24-hydroxylase, an enzyme responsible for removing cholesterol from the brain. Liver diseases are also related to brain aging, inducing changes in cholesterol metabolism in the brain and liver of rats. It has been suggested that late onset Alzheimer's disease is associated with metabolic syndrome. Non-alcoholic fatty liver is associated with lower total brain volume in the Framingham Heart Study offspring cohort study. Furthermore, disorders of cholesterol homeostasis in the adult brain are associated with neurological diseases such as Niemann-Pick, Alzheimer, Parkinson, Huntington and epilepsy. Apolipoprotein E (apoE) is important in transporting cholesterol from astrocytes to neurons in the etiology of sporadic Alzheimer's disease, an aging-related dementia. Desmosterol and 24S-hydroxycholesterol are reduced in ApoE KO hypercholesterolemic mice. ApOE KO mice have synaptic loss, cognitive dysfunction, and elevated plasma lipid levels that can affect brain function. In contrast to cholesterol itself, there is a continuous uptake of 27hydroxycholesterol in the brain as it crosses the blood-brain barrier and this flow can be an important link between intra- and extracerebral cholesterol homeostasis. Not surprisingly, changes in cholesterol metabolism occur simultaneously in the liver and nervous tissues and may be considered possible biomarkers of the liver and nervous system aging.

\section{INTRODUCTION}

Over the last few decades, there has been an increase in the elderly population. Between 2015 and 2050 the number of people aged 60 and over is expected to double worldwide (https://www.who.int/news-room/ fact-sheets/detail/ageing-and-health). The aging process is accompanied by numerous pathological changes and understanding them can help us improve the available treatments aimed at improving the quality of life.

Specifically, in lipid metabolism, advancing age is associated with a gradual increase in plasma concentrations of triglycerides (TG), cholesterol and low-density lipoprotein (LDL) [1]. It is suggested that the reduction in the concentration of total cholesterol in some studies with long-lived elderly individuals is due to the death of those with the highest blood cholesterol $[2,3]$. These changes may contribute to the increased risk of cardiovascular, neurological and liver disease observed in the elderly.

Cholesterol is one of the main components of the cell plasma membrane, giving it its physicochemical properties, such as fluidity and stability, however cholesterol is not evenly distributed in the membranes. It 
focuses on specialized sphingolipid-rich domains called lipid rafts and caveolae, which are involved in important cellular functions such as signaling across membranes $[4,5]$, regulation of membrane traffic, and signal transduction pathways that initiate in the membrane by stimulation or dimerization of receptors [6].

In addition to structural functions, enzymatic and nonenzymatic liver pathways give rise to several oxysterols, some of which are further metabolized into bile acids [7]. Oxidative cleavage of the cholesterol side chain generates pregnenolone, the common precursor to all other steroid hormones [8].

The body's cholesterol content is influenced by its ingestion, absorption, synthesis and excretion. Coordinately, modifications in one of these components lead to responses from the others in order to maintain cholesterol homeostasis. For example, the approximately four-fold increase in dietary intake of cholesterol reduced its synthesis, assessed in plasma lymphocytes, by $34 \%$ [9].

In blood vessels, chylomicrons (CHY) undergo the action of the lipoprotein lipase (LPL) enzyme, which hydrolyzes triglycerides (TG) and phospholipids (PL) present in these lipoproteins, making them available to peripheral tissues. This process reduces the size of the $\mathrm{CHY}$, forming remnant $\mathrm{CHY}$, which are quickly taken up by the B-E receptors and proteins related to the hepatic LDL receptor (LRP). The liver, in turn, synthesizes very low-density lipoprotein (VLDL) by conjugating TG, PL and cholesterol to apolipoprotein (apo) B100. Analogously to CHY, VLDL undergo LPL action in the circulation, originating intermediate density lipoproteins (IDL) and, ultimately, low-density lipoproteins (LDL). In human blood, LDL is the main carriers of cholesterol to peripheral tissues (Figure 1).

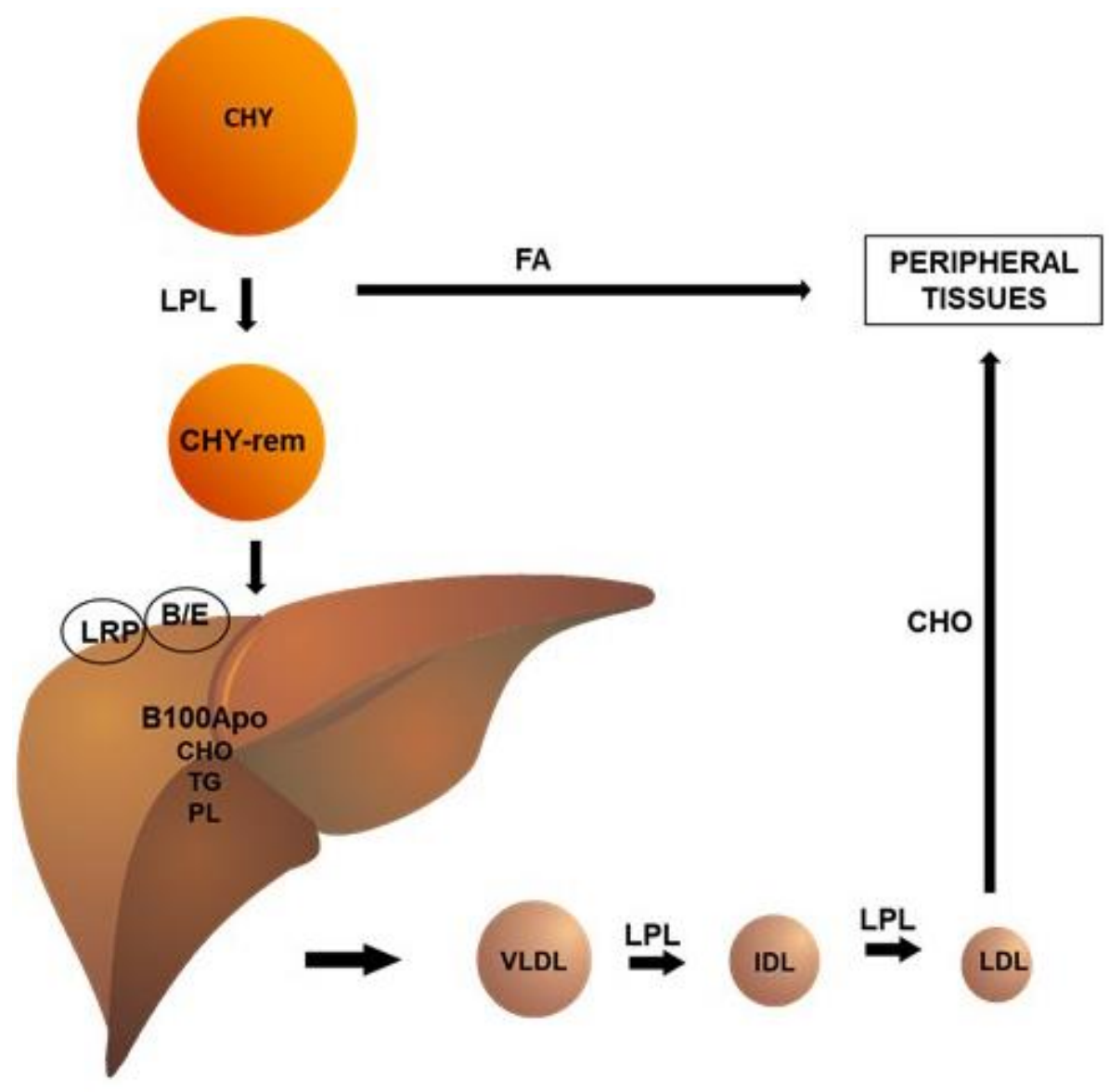

Figure 1. Chylomicrons (CHY) undergo the action of the lipoprotein lipase (LPL) enzyme, which hydrolyzes triglycerides (TG) and phospholipids (PL) present in these lipoproteins, making them available to peripheral tissues. This process reduces the size of the CHY, forming remnant $\mathrm{CHY}$, which are quickly taken up by the B/E receptors and proteins related to the hepatic LDL receptor (LRP). The liver, in turn, synthesizes very low-density lipoprotein (VLDL) by conjugating TG (triglycerides), PL (phospholipids), and CHO (cholesterol) to apolipoprotein (apo) B100. Analogously to CHY, VLDL undergo LPL action in the circulation, originating intermediate density lipoproteins (IDL) and, ultimately, low-density lipoproteins (LDL). In human blood, LDL is the main carriers of cholesterol to peripheral tissues. 
High-density lipoproteins (HDL) can be formed during the lipidation of apoA1, a protein synthesized in the liver and intestine, or during the metabolism of $\mathrm{CHY}$ and VLDL [10]. The main function of HDL is to promote the reverse transport of cholesterol, a process by which cholesterol is removed from peripheral tissues and sent to the liver for elimination in the feces. The excretion of cholesterol by the liver, in the form of bile acids, is the main form of elimination of cholesterol from the body (Figure 2).

The liver is the main organ responsible for synthesizing and eliminating excess cholesterol from the body. Cholesterol synthesis involves several molecular reactions and an efficient feedback control mechanism. The main regulatory step in cholesterol biosynthesis is the reduction of 3-hydroxy-3-methylglutaryl coenzyme A (HMG-CoA) to mevalonate, a reaction catalyzed by HMG-CoA reductase, an enzyme incorporated in the membrane of the endoplasmic reticulum (ER). The activity of HMG-CoAR is regulated by different mechanisms. Most important is the control of the rate of synthesis of HMGCoAR mRNA by the family of sterol

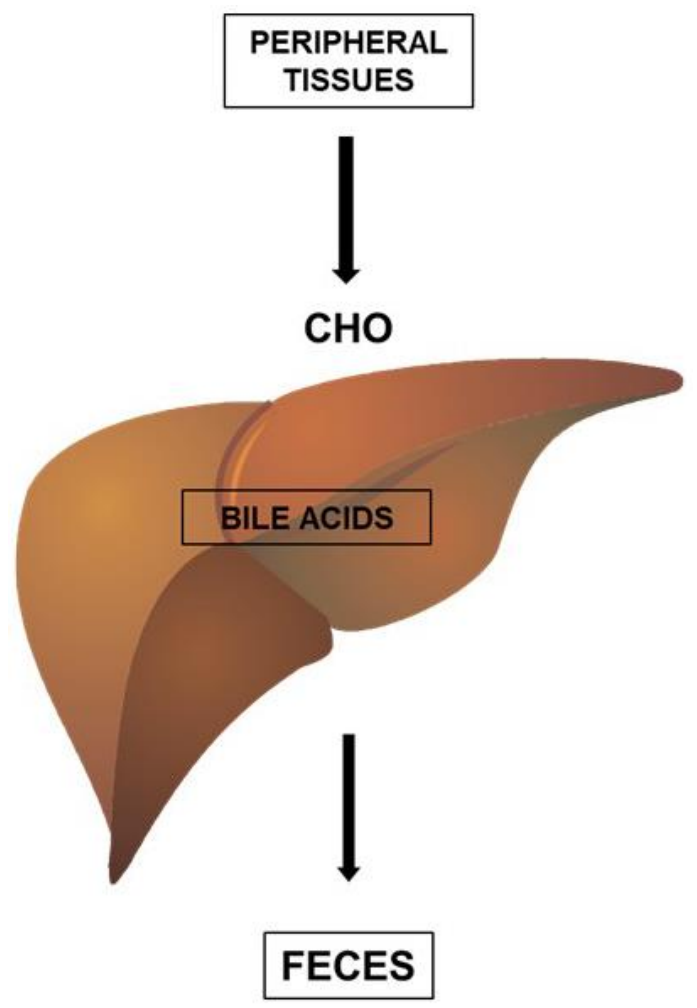

Figure 2. HDL promotes the reverse transport of cholesterol ( $\mathrm{CHO})$, a process by which cholesterol $(\mathrm{CHO})$ is removed from peripheral tissues and delivered to the liver for elimination in the feces. The excretion of cholesterol by the liver, in the form of bile acids, is an important form of elimination of cholesterol from the body. regulatory element binding proteins (SREBPs). SREBP2 is abundant in the brain and liver, while SREBP-1 is restricted to the liver. Specifically, SREBPs induce transcription of the HMG-CoAR gene binding to the sterol regulatory element (SRE) in the DNA. When the cholesterol concentration is sufficient to maintain cell homeostasis, the SREBPs bind to the SREBP cleavage activating protein (SCAP) in the ER membrane. When the cellular cholesterol content decreases, the sterol leaves its binding site to SCAP and the SREBP-SCAP complex moves to the Golgi, where two proteases (S1P and $\mathrm{S} 2 \mathrm{P}$ ) release the amino terminal domain of the transcription factor. This amino terminal peptide enters the nucleus and binds the SREs. When the cytoplasmic concentration of cholesterol increases, the sterol molecules bind to SCAP and prevent the complex's translocation to the Golgi, leading to a reduction in HMGCoAR transcription $[8,11]$.

Disturbances in cholesterol metabolism have been reported in several pathologies such as aging, diabetes mellitus, Alzheimer's disease, multiple sclerosis, osteoporosis, lung cancer, breast cancer, and infertility $[12,13]$. Furthermore, cholesterol metabolites may be more relevant than cholesterol itself in these pathologies [14-16].

\section{Changes in lipid metabolism with aging}

The mechanisms of lipid metabolism alterations with aging are not fully understood. The loss of lean mass and the increase in adipose tissue stimulate insulin resistance and allow a greater flow of fatty acid to the liver, resulting in increased synthesis of VLDL [17] and diminished removal rate of these lipoproteins from the plasma [17-19]. This is due to impairments in the activity of lipoprotein lipase [20] and reduced concentration of the hepatic LDL receptor secondary to the increase in PCSK9 [21], a protein responsible for signaling LDLr degradation. The longer half-life of lipoproteins in plasma possibly exposes lipoproteins to greater chemical changes, which contribute to reducing their affinity for their receptor [22, 23].

Reverse cholesterol transport (RCT), carried out by $\mathrm{HDL}$, is also diminished by aging. In vitro, it was observed that HDL isolated from elderly individuals had a lower capacity to remove cellular cholesterol when compared to HDL from 20-30 year old adults [24]. Recently, the in vivo RCT was evaluated in C57BL/6 mice at 3 or 20 weeks of age [25]. For this, J774 macrophages overloaded with labeled cholesterol were injected into the animals' peritoneum. The recovery of cholesterol in plasma, liver and feces represented RCT. After 48 hours of macrophages inoculation, the authors observed that older animals had lower concentrations of 
labeled cholesterol in the three compartments studied, showing less efficiency in the process of cholesterol removal and excretion with aging. It is important to note that there was no difference between the groups according to the HDLc concentrations. The two studies mentioned above attributed the results to the damage caused by aging or by HDL in the elderly on transporters ABCA1 and ABCG1 receptors involved in the delivery of cholesterol to HDLs.

\section{Cellular export of cholesterol by the liver and nervous system}

The liver is the only organ capable of metabolizing cholesterol into bile acids, representing approximately $1 / 3$ of the cholesterol eliminated from the body. The enzymatic conversion of cholesterol into bile acids by the microsomal cytochrome $\mathrm{P} 450$ system is the most important mechanism for the removal of cholesterol from the body, while the generation of 24hydroxycholesterol (24-HC) is the predominant form of cholesterol elimination by the central nervous system. The microsomal cytochrome $\mathrm{P} 450$ system is responsible for the enzymatic generation of oxysterols including $7 \alpha$ - hydroxycholesterol catalyzed by $7 \alpha$-hydroxylase (CYP7A1) in the liver, 24-HC in the brain and retina catalyzed by $24 \mathrm{~S}$-hydroxylase (CYP46A1), and mostly 27-hydroxycholesterol (27-HC) of tissues catalyzed by 27-hydroxylase (CYP27A1) [26, 27].

As in the brain, cholesterol synthesis in the liver is strongly regulated by the activity of HMGCoAR, while peripheral cholesterol catabolism is mainly carried out by CYP27A1, via the production of $27-\mathrm{HC}$ as the main catabolite. In contrast to cholesterol itself, there is a continuous uptake of $27-\mathrm{HC}$ into brain since it crosses the blood-brain barrier [28]. While there is an efflux of 24-HC from the brain to the peripheral circulation, there is also an inflow of 27-HC to the brain [29]. The flux of 27-HC into the brain may be an important link between intra and extracerebral cholesterol homeostasis [28].

In vitro conditions and in vivo experiments with different mouse models showed negative effects of the 27-HC in brain that include memory defects [30], reduced production of the 'memory protein' Arc (activity-regulated cytoskeleton-associated protein) in hippocampus [31, 32] and reduced brain uptake of glucose [31].

\section{Cholesterol metabolism in the liver is altered in more frequent pathologies such as aging and non-alcoholic fatty liver disease}

Other authors observed in human liver biopsies a negative correlation between age and $7 \alpha$-hydroxycholestenone, a marker of bile acid synthesis, a result that was attributed to lower expression of the enzyme CYP7A1 [33]. Since less cholesterol is eliminated in the form of bile acids, bile cholesterol saturation increases with age, increasing the risk of gallstones. These results suggest a reduction in the export of the cholesterol content from the liver with aging. If, in humans, the low removal cell rate elevates hepatic cholesterol concentration, this could explain, at least in part, the reduction in hepatic LDL receptor concentration and plasma (and presumably also hepatic) cholesterol synthesis markers.

At least in murine models, hepatic cholesterol concentration increases as a function of age [34-36]. In animals, aging is accompanied by increased expression of Niemann-Pick C1-like 1 (NPC1L1) in the enterocyte [37], probably increasing the absorption of intestinal cholesterol eliciting increased liver cholesterol uptake [36]. However, other authors reported that in human livers age was associated with reduced bile acids synthesis attributed to decreased expression of nuclear factor-4 and, consequently, to low cholesterol 7alphahydroxylase activity [33].

The aging process predisposes to functional and structural hepatic impairment. The most common liver disease, which affects a third of the world's population, is non-alcoholic fatty liver disease (NAFLD). This is characterized by the accumulation of fat in hepatocytes characterized as hepatic steatosis with active hepatic inflammation, known as non-alcoholic steatohepatitis. The prevalence of fatty liver disease has increased at alarming rates, along with obesity, diabetes and metabolic syndrome, becoming the second most common cause of cirrhosis after alcohol-related liver disease worldwide [38].

NAFLD patients present cholesterol metabolism alterations characterized by increased synthesis and decreased intestinal absorption of cholesterol [39] associated with liver fat content, regardless of body weight [39]. Alterations in cholesterol homeostasis pathways are linked to increased expression of HMGCR, and decreased expression of LDL receptors and bile acids synthesis [40].

NAFLD is a major health problem associated with obesity and metabolic syndrome, including insulin resistance and dyslipidemia. Lipid accumulation in hepatocytes causes liver damage and triggers inflammation, fibrosis and cirrhosis [41]. In addition to fatty acids and triglycerides, there is increased liver free cholesterol [42], with alterations in the cholesterol homeostasis pathways [40]. Measurements in mice livers indicate that cholesterol accumulates with both normal aging [36] and accelerated aging [34]. Other 
authors investigated the relationship between aging and cholesterol metabolism in the liver of 6-, 12-, 18- and 24-month-old male Wistar rats. They showed that the cholesterol concentration in the liver was not affected by aging, however, concentrations of the cholesterol precursors lanosterol and lathosterol increased, although desmosterol did not change [43].

\section{Cholesterol metabolism in the nervous system}

The brain is the richest organ in cholesterol with $25 \%$ of the total body cholesterol. Cholesterol is synthesized in the central nervous system, as the blood-brain barrier prevents its entry into the brain in the form of lipoproteins [44, 45]. Cholesterol is present in exceptionally high amounts in the myelin sheaths surrounding neuronal axons representing $25 \%$ of the lipid molecules in the plasma membrane of brain cells, while various phospholipids, sphingomyelin and glycolipids make up the remainder. In addition to being a critical structural component for plasma membranes, cholesterol is able to regulate membrane trafficking and signal transduction pathways that start in the plasma membrane by stimulating or dimerizing receptors [6].

Importantly, disorders of cholesterol homeostasis in the adult brain are associated with different neurological diseases, such as Niemann-Pick [46], Alzheimer [47], Parkinson [48], Huntington [49] and epilepsy [50].

Since cholesterol-loaded lipoproteins cannot cross the blood-brain barrier, the brain has developed regulation of cholesterol based on synthesis and a specific catabolism by the enzyme CYP46A1. Cholesterol is cleared from the brain as 24S-hydroxycholesterol (24S-HC). The enzyme responsible for this oxidation is CYP46A1, located in cytochrome P450, and expressed in certain types of neurons, namely, pyramidal neurons of the hippocampus and cortex, Purkinje cells of the cerebellum, and hippocampal and cerebellar interneurons [51]. Due to the decrease in hydrophobicity, 24S-HC besides diffusing from the blood-brain barrier to be eliminated by the liver, is a potent bioactive molecule capable of modifying different cell functions. 24S-HC affects the cell survival rate [5254], n-methyl D-Aspartate (NMDA) receptor activity $[55,56]$, exocytosis of vesicles [57] and LXR-induced transcriptional activity [58]. In addition to being the main by-product of brain cholesterol catabolism, 24S$\mathrm{HC}$ is a potent bioactive molecule with therapeutic implications as well as a biomarker in different neurological disorders [59].

It is widely accepted that in the adult brain, cholesterol synthesis in neurons is extremely low. Therefore, to satisfy their physiological needs, neurons need to import cholesterol from astrocytes. These cells have the molecular mechanism to secrete cholesterol-enriched apolipoproteins, and neurons express surface receptors for families of proteins related to low-density lipoprotein (LRP) and low-density lipoprotein (LDL) receptors, which bind charged apolipoproteins and cholesterol [59].

\section{Cholesterol metabolism in the central nervous system in aging}

As the brain ages, cognitive and motor performance decreases due to the accumulation of oxidative metabolism products. However, the aging brain contains few dead neurons, suggesting that aging must be accompanied by the activation or increase of neuronal survival mechanisms. Recent evidence points to the contribution of changes in membrane lipid composition to both age-dependent cognitive decline and robust neuronal survival [60].

Studies carried out in the human and rodent brain suggest that aging affects the cholesterol content in different regions, with the magnitude of variations depending on the analyzed sample, that is, total fraction, membrane fraction, lipid raft or synaptic fraction $[6,61,62]$.

A moderate loss of brain cholesterol, both in vitro and in vivo, occurs in the hippocampal neuron membranes of elderly rodents $[6,63]$. These findings agree with others reporting reduction in cholesterol levels from the age of 20 years onwards in the frontal and temporal cortices [64], and with a slight but significant reduction in the human hippocampus and cerebellum [62] or in brain synaptosomes derived from aged mice [6, 65]. Consistently, diminished cholesterol synthesis has been detected in the age-dependent human hippocampus [66] and increased levels of cholesterol 24-hydroxylase, the enzyme responsible for removing cholesterol in the brain [67] have been observed in the human brain and aged mice and in hippocampal neurons aging in vitro [63]. Furthermore, elevated levels of 24-HC were found in the plasma of elderly individuals [68].

Together, these results suggest that aging is accompanied by decreased synthesis and increased catabolism of cholesterol. However, changes in the amount of this lipid are highly variable during aging, ranging from no change to a $40 \%$ reduction [62].

The fluidity and asymmetry of cholesterol in the synaptic plasma membranes are altered in the aged mice with relative enrichment of cholesterol in the exofacial leaflet of synaptic membranes compared to young mice [69]. Increased cholesterol concentrations have been described in whole brain extracts from aged rats [70]. Together, these findings suggest that cholesterol levels 
respond differently during aging, depending on the metabolic needs of specific brain areas.

Relationship between aging and cholesterol metabolism in cortex and hippocampus, as well as in serum and liver of $6,12,18$ and 24-month-old male Wistar rats showed that during aging the concentrations of the cholesterol precursors lanosterol, lathosterol and desmosterol do not change in the cortex, except for desmosterol which decreased $44 \%$ in 18-month-old rats. In the hippocampus, aging was associated with a significant reduction in lanosterol and lathosterol concentrations at 24 months ( 28 and $25 \%$, respectively), as well as a significant decrease in desmosterol at 18 and 24 months (36 and 51\%, respectively) [43].

Although some studies have proposed an association between hypercholesterolemia and sporadic Alzheimer's Disease, the assumption that high concentrations of peripheral cholesterol impair the brain function remains controversial. In fact, the estimated number of adults in the US with cholesterol concentrations of $200 \mathrm{mg} / \mathrm{dL}$ or more is 99 million, and of that 32 million people have cholesterol levels of $240 \mathrm{mg} / \mathrm{dL}$ or more [71] whereas it is estimated only 5 million have Alzheimer's Disease [72]. Thus, if high serum cholesterol concentrations were a risk factor for Alzheimer's Disease, the incidence and prevalence of Alzheimer's Disease should be much higher. However, recent studies suggest that there may be a non-linear relationship between plasma cholesterol levels and cognitive functions [73-76].

The most abundant apolipoproteins in the brain are ApoE and ApoA1, while the liver produces and secretes a large set of apolipoproteins with specific functions. A study using human stem cell-derived astrocytes and neurons highlights the importance of apoE in transporting cholesterol from astrocytes to neurons in the etiology of sporadic Alzheimer's Disease, an agingrelated dementia [77]. ApoE KO mice show synaptic loss, cognitive dysfunction, and high plasma lipid levels that can affect the brain function. In ApoE KO mice, plasma concentrations of cholesterol and phytosterols (campesterol and sitosterol) are high. Cholesterol precursors (desmosterol and lathosterol) not detected in the plasma of control mice, are measurable in ApoE KO mice. Amounts of brain cholesterol, desmosterol, campesterol and $24 \mathrm{~S}-\mathrm{HC}$ are significantly lower in ApoE KO mice compared to wild-type controls. These results demonstrate that brain cholesterol content, rate of synthesis (desmosterol) and $24 \mathrm{~S}-\mathrm{HC}$ export are reduced in ApoE KO hypercholesterolemic mice [78].

CYP46A1 KO mice develop a considerable reduction in the concentration of $24 \mathrm{~S}-\mathrm{HC}$ in the brain, without another cholesterol metabolite to compensate for this oxysterol. In these mice, cholesterol concentrations are similar to those in wild-type animals. However, the concentrations of desmosterol, the precursor of cholesterol, and its metabolite formed by the closure of the mevalonate, 24S, 25-epoxycholesterol pathway are reduced [79].

In a study aiming to elucidate the etiology of sporadic Alzheimer's Disease, cholesterol and oxysterol concentrations were measured in the brain of ApoE $\varepsilon 2, \varepsilon 3$ and $\varepsilon 4$ humans and knock-in mice at 8 weeks and 1 year of age. No effect of ApoE genotype or age on cerebral cholesterol or on $24 \mathrm{~S}-\mathrm{HC}$ has been demonstrated. Concentrations of $27-\mathrm{HC}$ were elevated in 1-year-old animals for all ApoE genotypes [80]. Interestingly, lathosterol, a marker of cholesterol synthesis, was significantly reduced in 1-year-old animals for all ApoE genotypes. In addition, ApoE4 expressing mice exhibited lower concentrations of lathosterol compared to ApoE2 at both ages, and oxidized cholesterol metabolites were lower in ApoE2 mice compared to other genotypes at 8 weeks of age [80].

\section{Cholesterol metabolism is simultaneously altered in the liver and nervous system in aging}

Aging induces changes in cholesterol metabolism in the brain and liver of rats. In an experimental model, there was an age-induced increase in cholesterol synthesis in the liver, demonstrated by an increase in the concentrations of lanosterol and lathosterol, and no change in the concentration of desmosterol. The amounts of these liver sterols were smaller than in the brain regions. In the cortex and hippocampus, desmosterol was the predominant precursor of cholesterol while in the liver, lathosterol was the most abundant precursor. This proportion remained stable during aging. This study showed that aging diminishes cholesterol synthesis in the hippocampus, demonstrated by a reduction in the concentration of desmosterol, which could reflect a reduction in age-related synaptic plasticity. The results showed that aging influences cholesterol synthesis in different ways in the brain and periphery, proving that cholesterol metabolism in the brain is autonomous [43].

Liver diseases, even in pre-cirrhotic stages, are also related to brain aging [81-87]. NAFLD was associated with poor cognitive performance independent of CVD and its risk factors when analyzing data from the Third National Health and Nutrition Examination Survey (NHANES III), covering a representative sample of the general US population investigating the relationships between NAFLD determined by ultrasound and cognitive impairment assessed by three computerized tests [84]. Decreased brain activity measured using 
infrared spectroscopy was observed in 24 female NAFLD patients compared to 15 healthy control females [85] and healthy middle-aged adults (67 \pm 9 years) in the descending cohort study of Framingham Heart Study NAFLD associated with lower total brain volume, independent of visceral adipose tissue and cardiometabolic risk factors, pointing to a possible link between hepatic steatosis and cerebral aging [86] Another study that evaluated the cross-sectional relationship of NAFLD and liver fibrosis with cognitive performance among Framingham Study participants aged $61 \pm 12$ years, free from dementia and stroke and without excessive alcohol intake, showed that participants with high risk of advanced fibrosis had worse cognitive function compared with those at low risk [87].

NAFLD, characterized by accumulation of extra fat in liver cells that can lead to inflammation, liver fibrosis, cirrhosis, and liver cancer, is an obesity-related condition that has reached epidemic proportions [88, 89], and coexists with classic CVD risk factors [90]. A study in participants CARDIA study (Coronary Artery Risk Development in Young Adults) [91] that evaluated cognitive function and computed chest and abdomen tomography scans as part of the 25-year follow-up examination, and with cognitive function reassessed in the 30-year follow-up examination, showed that the inverse associations between NAFLD and cognitive scores were attenuated after adjustment for CVD risk factors, with the last predictor of worse cognitive performance both at baseline and throughout follow-up [92].

Ethical and methodological limitations do not allow direct measurements of synthesis and cholesterol in the brain and liver in humans. However, in rats, aging simultaneously induces changes in cholesterol metabolism in the brain and liver [43]. While the results showed an increase in cholesterol synthesis in the liver, in the brain there was a decrease in the hippocampus of aged rats. This study corroborates those where NAFLD was associated with brain aging characterized by cognitive impairment, reduced brain activity, and decreased brain volume [81-87], confirming that aging influences cholesterol synthesis in different ways in the brain and periphery, as well as that cholesterol metabolism in the brain is autonomous.

Alterations in the regulation of hepatic bile acid metabolism in metabolic syndrome [93, 94] and in non-alcoholic hepatic steatosis [95] have been reported in several investigations in humans, including in experimental models [96-98]. More recently, Alzheimer's disease late onset has been suggested to be associated with metabolic syndrome [99]. In light of these results, it is not surprising that changes in cholesterol metabolism occur simultaneously with hepatic and neurological aging. Furthermore, in rats with aging, cholesterol accumulates in the liver, while the opposite occurs in the brain [43].

Neurological and hepatic alterations in cholesterol metabolism have been reported, the consequences of which for neurological diseases need to be explored. For example, bile acid metabolism appears to be decreased in dementia [100], and is related to Alzheimer's disease [101]. Also, enzymes related to cholesterol metabolism, such as PCSK9, could be linked to Alzheimer's disease [102]. Consequently, the connection of disorders of cholesterol metabolism in the liver and the central nervous system deserves investigation.

Future research should look for blood markers that identify the simultaneity of liver and neuronal aging.

\section{AUTHOR CONTRIBUTIONS}

V.S.M. conceived, wrote, edited the manuscript, G.S.F. wrote and reviewed and E.C.R.Q. conceived, wrote and revised the manuscript.

\section{CONFLICTS OF INTEREST}

The authors declare no conflicts of interest.

\section{REFERENCES}

1. Liu HH, Li JJ. Aging and dyslipidemia: a review of potential mechanisms. Ageing Res Rev. 2015; 19:43-52.

https://doi.org/10.1016/j.arr.2014.12.001 PMID:25500366

2. Tilvis RS, Valvanne JN, Strandberg TE, Miettinen TA. Prognostic significance of serum cholesterol, lathosterol, and sitosterol in old age; a 17-year population study. Ann Med. 2011; 43:292-301. https://doi.org/10.3109/07853890.2010.546363 PMID:21254906

3. Yandrapalli S, Gupta S, Andries G, Cooper HA, Aronow WS. Drug Therapy of Dyslipidemia in the Elderly. Drugs Aging. 2019; 36:321-40. https://doi.org/10.1007/s40266-018-00632-x PMID:30613912

4. Mesa-Herrera F, Taoro-González L, Valdés-Baizabal C, Diaz M, Marín R. Lipid and Lipid Raft Alteration in Aging and Neurodegenerative Diseases: A Window for the Development of New Biomarkers. Int J Mol Sci. 2019; 20:3810.

https://doi.org/10.3390/ijms20153810 PMID: 
5. Wang H. Lipid rafts: a signaling platform linking cholesterol metabolism to synaptic deficits in autism spectrum disorders. Front Behav Neurosci. 2014; 8:104.

https://doi.org/10.3389/fnbeh.2014.00104

PMID:24723866

6. Sodero AO, Trovò L, lannilli F, Van Veldhoven P, Dotti CG, Martin MG. Regulation of tyrosine kinase B activity by the Cyp46/cholesterol loss pathway in mature hippocampal neurons: relevance for neuronal survival under stress and in aging. J Neurochem. 2011; 116:747-55.

https://doi.org/10.1111/i.1471-4159.2010.07079.x PMID:21214568

7. Luu W, Sharpe L, Capell-Hattam I, Gelissen IC, Brown AJ. Oxysterols: Old Tale, New Twists. Annu Rev Pharmacol Toxicol. 2016; 56:447-67.

https://doi.org/10.1146/annurev-pharmtox-010715103233 PMID: 26738477

8. Luo J, Yang H, Song BL. Mechanisms and regulation of cholesterol homeostasis. Nat Rev Mol Cell Biol. 2020; 21:225-45.

https://doi.org/10.1038/s41580-019-0190-7 PMID:31848472

9. Parker TS, McNamara DJ, Brown C, Garrigan O, Kolb R, Batwin $\mathrm{H}$, Ahrens EH Jr. Mevalonic acid in human plasma: relationship of concentration and circadian rhythm to cholesterol synthesis rates in man. Proc Natl Acad Sci USA. 1982; 79:3037-41.

https://doi.org/10.1073/pnas.79.9.3037

PMID: 6953446

10. Holleboom AG, Vergeer M, Hovingh GK, Kastelein JJ, Kuivenhoven JA. The value of HDL genetics. Curr Opin Lipidol. 2008; 19:385-94.

https://doi.org/10.1097/MOL.0b013e328306a043 PMID:18607186

11. Brown MS, Goldstein JL. The SREBP pathway: regulation of cholesterol metabolism by proteolysis of a membrane-bound transcription factor. Cell. 1997; 89:331-40.

https://doi.org/10.1016/s0092-8674(00)80213-5 PMID: $\underline{9150132}$

12. Zarrouk A, Vejux A, Mackrill J, O'Callaghan Y, Hammami M, O'Brien N, Lizard G. Involvement of oxysterols in age-related diseases and ageing processes. Ageing Res Rev. 2014; 18:148-62. https://doi.org/10.1016/i.arr.2014.09.006 PMID:25305550

13. Samadi A, Sabuncuoglu S, Samadi M, Isikhan SY, Chirumbolo S, Peana M, Lay I, Yalcinkaya A, Bjørklund G. A Comprehensive Review on Oxysterols and Related Diseases. Curr Med Chem. 2021; 28:110-36. https://doi.org/10.2174/0929867327666200316142659 PMID:32175830

14. Wang Y, Yutuc E, Griffiths WJ. Cholesterol metabolism pathways - are the intermediates more important than the products? FEBS J. 2021; 288:3727-45. https://doi.org/10.1111/febs.15727 PMID:33506652

15. Zarrouk A, Debbabi $M$, Bezine $M$, Karym EM, Badreddine A, Rouaud O, Moreau T, Cherkaoui-Malki M, El Ayeb M, Nasser B, Hammami M, Lizard G. Lipid Biomarkers in Alzheimer's Disease. Curr Alzheimer Res. 2018; 15:303-12. https://doi.org/10.2174/1567205014666170505101426 PMID:28474568

16. Sassi K, Nury T, Samadi M, Fennira FBA, Vejux A, Lizard G. Cholesterol Derivatives as Promising Anticancer Agents in Glioblastoma Metabolic Therapy. In: Debinski W, editor. Gliomas. Brisbane (AU): Exon Publications; 2021. Chapter 6. PMID:34038051

17. Millar JS, Lichtenstein AH, Cuchel M, Dolnikowski GG, Hachey DL, Cohn JS, Schaefer EJ. Impact of age on the metabolism of VLDL, IDL, and LDL apolipoprotein B-100 in men. J Lipid Res. 1995; 36:1155-67.

PMID:7665994

18. Pinto LB, Wajngarten $M$, Silva $E L$, Vinagre $C C$, Maranhão RC. Plasma kinetics of a cholesterol-rich emulsion in young, middle-aged, and elderly subjects. Lipids. 2001; 36:1307-11.

https://doi.org/10.1007/s11745-001-0845-y PMID:11834081

19. Vinagre CG, Freitas FR, de Mesquita $\mathrm{CH}$, Vinagre JC, Mariani AC, Kalil-Filho R, Maranhão RC. Removal of Chylomicron Remnants from the Bloodstream is Delayed in Aged Subjects. Aging Dis. 2018; 9:748-54. https://doi.org/10.14336/AD.2017.1003 PMID:30090662

20. Dallinga-Thie GM, Franssen $R$, Mooij HL, Visser ME, Hassing HC, Peelman F, Kastelein JJ, Péterfy $M$, Nieuwdorp $M$. The metabolism of triglyceride-rich lipoproteins revisited: new players, new insight. Atherosclerosis. 2010; 211:1-8.

https://doi.org/10.1016/j.atherosclerosis.2009.12.027 PMID:20117784

21. Horton JD, Cohen JC, Hobbs HH. Molecular biology of PCSK9: its role in LDL metabolism. Trends Biochem Sci. 2007; 32:71-7. https://doi.org/10.1016/i.tibs.2006.12.008 PMID:17215125

22. Kortlandt W, Benschop C, van Rijn HJ, Erkelens DW. Glycated low density lipoprotein catabolism is increased in rabbits with alloxan-induced diabetes mellitus. Diabetologia. 1992; 35:202-7. 
https://doi.org/10.1007/BF00400918

PMID: 1563579

23. Sasaki J, Cottam GL. Glycosylation of LDL decreases its ability to interact with high-affinity receptors of human fibroblasts in vitro and decreases its clearance from rabbit plasma in vivo. Biochim Biophys Acta. 1982; 713:199-207.

https://doi.org/10.1016/0005-2760(82)90237-5 PMID: $\underline{6295495}$

24. Berrougui $H$, Isabelle $M$, Cloutier M, Grenier G, Khalil A. Age-related impairment of HDL-mediated cholesterol efflux. J Lipid Res. 2007; 48:328-36.

https://doi.org/10.1194/ilr.M600167-JLR200 PMID:17093293

25. Simo OK, Berrougui $H$, Fulop $T$, Khalil A. The Susceptibility to Diet-Induced Atherosclerosis is Exacerbated with Aging in C57B1/6 Mice. Biomedicines. 2021; 9:487. https://doi.org/10.3390/biomedicines 9050487 PMID: $\underline{3946646}$

26. Björkhem I, Diczfalusy U. Oxysterols: friends, foes, or just fellow passengers? Arterioscler Thromb Vasc Biol. 2002; 22:734-42.

https://doi.org/10.1161/01.atv.0000013312.32196.49 PMID:12006384

27. Norlin M, Wikvall K. Enzymes in the conversion of cholesterol into bile acids. Curr Mol Med. 2007; 7:199-218.

https://doi.org/10.2174/156652407780059168 PMID:17346171

28. Heverin M, Meaney S, Lütjohann D, Diczfalusy U, Wahren J, Björkhem I. Crossing the barrier: net flux of 27-hydroxycholesterol into the human brain. J Lipid Res. 2005; 46:1047-52.

https://doi.org/10.1194/ilr.M500024-JLR200 PMID:15741649

29. Gamba P, Testa G, Gargiulo S, Staurenghi E, Poli G, Leonarduzzi G. Oxidized cholesterol as the driving force behind the development of Alzheimer's disease. Front Aging Neurosci. 2015; 7:119.

https://doi.org/10.3389/fnagi.2015.00119 PMID:26150787

30. Heverin M, Maioli S, Pham T, Mateos L, Camporesi E, Ali Z, Winblad B, Cedazo-Minguez A, Björkhem I. 27hydroxycholesterol mediates negative effects of dietary cholesterol on cognition in mice. Behav Brain Res. 2015; 278:356-9.

https://doi.org/10.1016/j.bbr.2014.10.018 PMID:25453744

31. Ismail MA, Mateos L, Maioli S, Merino-Serrais P, Ali Z, Lodeiro $M$, Westman E, Leitersdorf E, Gulyás B, OlofWahlund L, Winblad B, Savitcheva I, Björkhem I,
Cedazo-Mínguez A. 27-Hydroxycholesterol impairs neuronal glucose uptake through an IRAP/GLUT4 system dysregulation. J Exp Med. 2017; 214:699-717. https://doi.org/10.1084/jem.20160534 PMID:28213512

32. Mateos L, Akterin S, Gil-Bea FJ, Spulber S, Rahman A, Björkhem I, Schultzberg M, Flores-Morales A, CedazoMínguez A. Activity-regulated cytoskeleton-associated protein in rodent brain is down-regulated by high fat diet in vivo and by 27 -hydroxycholesterol in vitro. Brain Pathol. 2009; 19:69-80. https://doi.org/10.1111/i.1750-3639.2008.00174.x PMID: 18503570

33. Bertolotti M, Gabbi C, Anzivino C, Crestani M, Mitro N, Del Puppo M, Godio C, De Fabiani E, Macchioni D, Carulli L, Rossi A, Ricchi M, Loria P, Carulli N. Agerelated changes in bile acid synthesis and hepatic nuclear receptor expression. Eur J Clin Invest. 2007; 37:501-8.

https://doi.org/10.1111/i.1365-2362.2007.01808.x PMID: 17537158

34. Kuhla A, Blei T, Jaster R, Vollmar B. Aging is associated with a shift of fatty metabolism toward lipogenesis. J Gerontol A Biol Sci Med Sci. 2011; 66:1192-200.

https://doi.org/10.1093/gerona/glr124 PMID:21835806

35. Mulas MF, Demuro G, Mulas C, Putzolu M, Cavallini G, Donati A, Bergamini E, Dessi S. Dietary restriction counteracts age-related changes in cholesterol metabolism in the rat. Mech Ageing Dev. 2005; 126:648-54.

https://doi.org/10.1016/j.mad.2004.11.010 PMID:15888318

36. Seo E, Kang H, Choi H, Choi W, Jun HS. Reactive oxygen species-induced changes in glucose and lipid metabolism contribute to the accumulation of cholesterol in the liver during aging. Aging Cell. 2019; 18:e12895.

https://doi.org/10.1111/acel.12895 PMID:30609251

37. Duan LP, Wang HH, Ohashi A, Wang DQ. Role of intestinal sterol transporters Abcg5, Abcg8, and Npc1l1 in cholesterol absorption in mice: gender and age effects. Am J Physiol Gastrointest Liver Physiol. 2006; 290:G269-76.

https://doi.org/10.1152/ajpgi.00172.2005 PMID:16179600

38. Seen TK, Sayed M, Bilal M, Reyes JV, Bhandari $P$, Lourdusamy V, Al-Khazraji A, Syed U, Sattar Y, Bansal R. Clinical indicators for progression of nonalcoholic steatohepatitis to cirrhosis. World J Gastroenterol. 2021; 27:3238-48. https://doi.org/10.3748/wig.v27.i23.3238 PMID:34163108 
39. Simonen $P$, Kotronen A, Hallikainen M, Sevastianova K, Makkonen J, Hakkarainen A, Lundbom N, Miettinen TA, Gylling H, Yki-Järvinen $H$. Cholesterol synthesis is increased and absorption decreased in non-alcoholic fatty liver disease independent of obesity. J Hepatol. 2011; 54:153-9.

https://doi.org/10.1016/i.jhep.2010.05.037

PMID:20947198

40. Min HK, Kapoor A, Fuchs M, Mirshahi F, Zhou H, Maher J, Kellum J, Warnick R, Contos MJ, Sanyal AJ. Increased hepatic synthesis and dysregulation of cholesterol metabolism is associated with the severity of nonalcoholic fatty liver disease. Cell Metab. 2012; 15:665-74.

https://doi.org/10.1016/i.cmet.2012.04.004 PMID:22560219

41. Malhotra P, Gill RK, Saksena S, Alrefai WA. Disturbances in Cholesterol Homeostasis and Nonalcoholic Fatty Liver Diseases. Front Med (Lausanne). 2020; 7:467.

https://doi.org/10.3389/fmed.2020.00467

PMID:32984364

42. Puri P, Baillie RA, Wiest MM, Mirshahi F, Choudhury J, Cheung O, Sargeant C, Contos MJ, Sanyal AJ. A lipidomic analysis of nonalcoholic fatty liver disease. Hepatology. 2007; 46:1081-90.

https://doi.org/10.1002/hep.21763

PMID:17654743

43. Smiljanic K, Vanmierlo $T$, Djordjevic AM, Perovic $M$, Loncarevic-Vasiljkovic N, Tesic V, Rakic L, Ruzdijic S, Lutjohann D, Kanazir S. Aging induces tissue-specific changes in cholesterol metabolism in rat brain and liver. Lipids. 2013; 48:1069-77.

https://doi.org/10.1007/s11745-013-3836-9

PMID:24057446

44. Björkhem I, Meaney S. Brain cholesterol: long secret life behind a barrier. Arterioscler Thromb Vasc Biol. 2004; 24:806-15.

https://doi.org/10.1161/01.ATV.0000120374.59826.1b PMID:14764421

45. Dietschy JM, Turley SD. Thematic review series: brain Lipids. Cholesterol metabolism in the central nervous system during early development and in the mature animal. J Lipid Res. 2004; 45:1375-97.

https://doi.org/10.1194/ilr.R400004-JLR200 PMID: 15254070

46. Maxfield FR, Tabas I. Role of cholesterol and lipid organization in disease. Nature. 2005; 438:612-21. https://doi.org/10.1038/nature04399 PMID:16319881

47. Arenas F, Garcia-Ruiz C, Fernandez-Checa JC. Intracellular Cholesterol Trafficking and Impact in Neurodegeneration. Front Mol Neurosci. 2017; 10:382. https://doi.org/10.3389/fnmol.2017.00382 PMID:29204109

48. Doria M, Maugest L, Moreau T, Lizard G, Vejux A. Contribution of cholesterol and oxysterols to the pathophysiology of Parkinson's disease. Free Radic Biol Med. 2016; 101:393-400.

https://doi.org/10.1016/i.freeradbiomed.2016.10.008 PMID:27836779

49. Valenza M, Cattaneo E. Emerging roles for cholesterol in Huntington's disease. Trends Neurosci. 2011; 34:474-86.

https://doi.org/10.1016/i.tins.2011.06.005 PMID:21774998

50. Scicchitano F, Constanti A, Citraro R, De Sarro G, Russo E. Statins and epilepsy: preclinical studies, clinical trials and statin-anticonvulsant drug interactions. Curr Drug Targets. 2015; 16:747-56.

https://doi.org/10.2174/1389450116666150330114850 PMID:25901524

51. Russell DW, Halford RW, Ramirez DM, Shah R, Kotti T. Cholesterol 24-hydroxylase: an enzyme of cholesterol turnover in the brain. Annu Rev Biochem. 2009; 78:1017-40.

https://doi.org/10.1146/annurev.biochem.78.072407. 103859 PMID:19489738

52. Vo DK, Urano Y, Takabe W, Saito Y, Noguchi N. 24(S)Hydroxycholesterol induces RIPK1-dependent but MLKL-independent cell death in the absence of caspase-8. Steroids. 2015; 99:230-7.

https://doi.org/10.1016/i.steroids.2015.02.007 PMID:25697054

53. Yamanaka K, Urano Y, Takabe W, Saito Y, Noguchi N. Induction of apoptosis and necroptosis by 24(S)hydroxycholesterol is dependent on activity of acylCoA:cholesterol acyltransferase 1. Cell Death Dis. 2014; 5:e990.

https://doi.org/10.1038/cddis.2013.524

PMID:24407243

54. Yamanaka K, Saito Y, Yamamori T, Urano Y, Noguchi N. 24(S)-hydroxycholesterol induces neuronal cell death through necroptosis, a form of programmed necrosis. J Biol Chem. 2011; 286:24666-73.

https://doi.org/10.1074/ibc.M111.236273

PMID:21613228

55. Emnett CM, Eisenman LN, Mohan J, Taylor AA, Doherty JJ, Paul SM, Zorumski CF, Mennerick S. Interaction between positive allosteric modulators and trapping blockers of the NMDA receptor channel. $\mathrm{Br} J$ Pharmacol. 2015; 172:1333-47. https://doi.org/10.1111/bph.13007 PMID:25377730

56. Paul SM, Doherty JJ, Robichaud AJ, Belfort GM, Chow BY, Hammond RS, Crawford DC, Linsenbardt AJ, Shu HJ, 
Izumi Y, Mennerick SJ, Zorumski CF. The major brain cholesterol metabolite 24(S)-hydroxycholesterol is a potent allosteric modulator of $\mathrm{N}$-methyl-D-aspartate receptors. J Neurosci. 2013; 33:17290-300.

https://doi.org/10.1523/JNEUROSCl.2619-13.2013

PMID:24174662

57. Ma MT, Zhang J, Farooqui AA, Chen P, Ong WY. Effects of cholesterol oxidation products on exocytosis. Neurosci Lett. 2010; 476:36-41.

https://doi.org/10.1016/i.neulet.2010.03.078

PMID:20380872

58. Okabe A, Urano Y, Itoh S, Suda N, Kotani R, Nishimura $Y$, Saito $Y$, Noguchi N. Adaptive responses induced by 24S-hydroxycholesterol through liver $X$ receptor pathway reduce 7-ketocholesterol-caused neuronal cell death. Redox Biol. 2013; 2:28-35.

https://doi.org/10.1016/j.redox.2013.11.007 PMID:24371802

59. Sodero AO. 24S-hydroxycholesterol: Cellular effects and variations in brain diseases. J Neurochem. 2021; 157:899-918.

https://doi.org/10.1111/inc.15228 PMID:33118626

60. Ledesma MD, Martin MG, Dotti CG. Lipid changes in the aged brain: effect on synaptic function and neuronal survival. Prog Lipid Res. 2012; 51:23-35. https://doi.org/10.1016/i.plipres.2011.11.004 PMID:22142854

61. Díaz M, Fabelo N, Ferrer I, Marín R. "Lipid raft aging" in the human frontal cortex during nonpathological aging: gender influences and potential implications in Alzheimer's disease. Neurobiol Aging. 2018; 67:42-52. https://doi.org/10.1016/j.neurobiolaging.2018.02.022 PMID:29627763

62. Söderberg M, Edlund C, Kristensson K, Dallner G. Lipid compositions of different regions of the human brain during aging. J Neurochem. 1990; 54:415-23. https://doi.org/10.1111/j.1471-4159.1990.tb01889.x PMID:2299344

63. Martin MG, Perga S, Trovò L, Rasola A, Holm P, Rantamäki T, Harkany T, Castrén E, Chiara F, Dotti CG. Cholesterol loss enhances TrkB signaling in hippocampal neurons aging in vitro. Mol Biol Cell. 2008; 19:2101-12.

https://doi.org/10.1091/mbc.e07-09-0897

PMID:18287532

64. Svennerholm L, Boström K, Jungbjer B, Olsson L. Membrane lipids of adult human brain: lipid composition of frontal and temporal lobe in subjects of age 20 to 100 years. J Neurochem. 1994; 63:1802-11.

https://doi.org/10.1046/i.1471-4159.1994.63051802.x PMID:7931336
65. Yamamoto N, Matsubara T, Sato T, Yanagisawa K. Agedependent high-density clustering of GM1 ganglioside at presynaptic neuritic terminals promotes amyloid beta-protein fibrillogenesis. Biochim Biophys Acta. 2008; 1778:2717-26.

https://doi.org/10.1016/j.bbamem.2008.07.028 PMID:18727916

66. Thelen KM, Falkai $\mathrm{P}$, Bayer TA, Lütjohann $\mathrm{D}$. Cholesterol synthesis rate in human hippocampus declines with aging. Neurosci Lett. 2006; 403:15-9. https://doi.org/10.1016/i.neulet.2006.04.034 PMID: 16701946

67. Bjorkhem I, Diczfalusy U. 24(S),25-epoxycholesterol--a potential friend. Arterioscler Thromb Vasc Biol. 2004; 24:2209-10.

https://doi.org/10.1161/01.ATV.0000148704.72481.28 PMID: 15576644

68. Lütjohann D, Breuer O, Ahlborg G, Nennesmo I, Sidén A, Diczfalusy $U$, Björkhem I. Cholesterol homeostasis in human brain: evidence for an agedependent flux of 24S-hydroxycholesterol from the brain into the circulation. Proc Natl Acad Sci USA. 1996; 93:9799-804.

https://doi.org/10.1073/pnas.93.18.9799

PMID:8790411

69. Igbavboa U, Avdulov NA, Schroeder F, Wood WG. Increasing age alters transbilayer fluidity and cholesterol asymmetry in synaptic plasma membranes of mice. J Neurochem. 1996; 66:1717-25.

https://doi.org/10.1046/i.1471-4159.1996.66041717.x PMID: $\underline{8627330}$

70. Aureli T, Di Cocco ME, Capuani G, Ricciolini R, Manetti C, Miccheli A, Conti F. Effect of long-term feeding with acetyl-L-carnitine on the age-related changes in rat brain lipid composition: a study by 31P NMR spectroscopy. Neurochem Res. 2000; 25:395-9. https://doi.org/10.1023/a:1007501306623 PMID:10761985

71. Go AS, Mozaffarian D, Roger VL, Benjamin EJ, Berry JD, Borden WB, Bravata DM, Dai S, Ford ES, Fox CS, Franco $\mathrm{S}$, Fullerton HJ, Gillespie C, et al, and American Heart Association Statistics Committee and Stroke Statistics Subcommittee. Executive summary: heart disease and stroke statistics--2013 update: a report from the American Heart Association. Circulation. 2013; 127:143-52.

https://doi.org/10.1161/CIR.0b013e318282ab8f PMID:23283859

72. Hebert LE, Weuve J, Scherr PA, Evans DA. Alzheimer disease in the United States (2010-2050) estimated using the 2010 census. Neurology. 2013; 80:1778-83. https://doi.org/10.1212/WNL.0b013e31828726f5 PMID:23390181 
73. Lu Y, An Y, Yu H, Che F, Zhang X, Rong H, Xi Y, Xiao R. Sex-specific nonlinear associations between serum lipids and different domains of cognitive function in middle to older age individuals. Metab Brain Dis. 2017; 32:1089-97.

https://doi.org/10.1007/s11011-017-9999-y PMID:28374237

74. Marcum ZA, Walker R, Bobb JF, Sin MK, Gray SL, Bowen JD, McCormick W, McCurry SM, Crane PK, Larson EB. Serum Cholesterol and Incident Alzheimer's Disease: Findings from the Adult Changes in Thought Study. J Am Geriatr Soc. 2018; 66:2344-52. https://doi.org/10.1111/igs.15581 PMID:30289959

75. Wendell CR, Waldstein SR, Zonderman AB. Nonlinear longitudinal trajectories of cholesterol and neuropsychological function. Neuropsychology. 2014; 28:106-12. https://doi.org/10.1037/neu0000002 PMID:24188111

76. Wendell CR, Zonderman AB, Katzel LI, Rosenberger WF, Plamadeala VV, Hosey MM, Waldstein SR. Nonlinear associations between plasma cholesterol levels and neuropsychological function. Neuropsychology. 2016; 30:980-7.

https://doi.org/10.1037/neu0000298 PMID:27280580

77. Zhao J, Davis MD, Martens YA, Shinohara M, GraffRadford NR, Younkin SG, Wszolek ZK, Kanekiyo T, Bu G. APOE $\varepsilon 4 / \varepsilon 4$ diminishes neurotrophic function of human iPSC-derived astrocytes. Hum Mol Genet. 2017; 26:2690-700.

https://doi.org/10.1093/hmg/ddx155

PMID:28444230

78. Nunes VS, Cazita PM, Catanozi S, Nakandakare ER, Quintão EC. Decreased content, rate of synthesis and export of cholesterol in the brain of apoE knockout mice. J Bioenerg Biomembr. 2018; 50:283-7.

https://doi.org/10.1007/s10863-018-9757-9

PMID:29675736

79. Meljon A, Wang Y, Griffiths WJ. Oxysterols in the brain of the cholesterol 24-hydroxylase knockout mouse. Biochem Biophys Res Commun. 2014; 446:768-74. https://doi.org/10.1016/j.bbrc.2014.01.153 PMID:24491562

80. Jenner $A M, \operatorname{Lim} W L, N g$ MP, Wenk MR, Shui G, Sharman MJ, Gandy SE, Martins RN. The effect of APOE genotype on brain levels of oxysterols in young and old human APOE epsilon2, epsilon3 and epsilon4 knock-in mice. Neuroscience. 2010; 169:109-15.

https://doi.org/10.1016/i.neuroscience.2010.04.026 PMID:20416362

81. Newton JL, Hollingsworth KG, Taylor R, El-Sharkawy AM, Khan ZU, Pearce R, Sutcliffe K, Okonkwo O, Davidson A, Burt J, Blamire AM, Jones D. Cognitive impairment in primary biliary cirrhosis: symptom impact and potential etiology. Hepatology. 2008; 48:541-9.

https://doi.org/10.1002/hep.22371

PMID:18563843

82. Yilmaz Y, Ozdogan O. Liver disease as a risk factor for cognitive decline and dementia: an under-recognized issue. Hepatology. 2009; 49:698.

https://doi.org/10.1002/hep.22752 PMID:19177568

83. Bertolotti M, Lonardo A, Mussi C, Baldelli E, Pellegrini E, Ballestri S, Romagnoli D, Loria P. Nonalcoholic fatty liver disease and aging: epidemiology to management. World J Gastroenterol. 2014; 20:14185-204. https://doi.org/10.3748/wjg.v20.i39.14185 PMID:25339806

84. Seo SW, Gottesman RF, Clark JM, Hernaez R, Chang Y, Kim C, Ha KH, Guallar E, Lazo M. Nonalcoholic fatty liver disease is associated with cognitive function in adults. Neurology. 2016; 86:1136-42. https://doi.org/10.1212/WNL.0000000000002498 PMID:26911638

85. Takahashi A, Kono S, Wada A, Oshima S, Abe K, Imaizumi H, Fujita M, Hayashi M, Okai K, Miura I, Yabe $\mathrm{H}$, Ohira $\mathrm{H}$. Reduced brain activity in female patients with non-alcoholic fatty liver disease as measured by near-infrared spectroscopy. PLoS One. 2017; 12:e0174169.

https://doi.org/10.1371/journal.pone.0174169 PMID:28376101

86. Weinstein G, Zelber-Sagi S, Preis SR, Beiser AS, DeCarli C, Speliotes EK, Satizabal CL, Vasan RS, Seshadri S. Association of Nonalcoholic Fatty Liver Disease With Lower Brain Volume in Healthy Middle-aged Adults in the Framingham Study. JAMA Neurol. 2018; 75:97-104.

https://doi.org/10.1001/jamaneurol.2017.3229 PMID:29159396

87. Weinstein G, Davis-Plourde K, Himali JJ, Zelber-Sagi S, Beiser AS, Seshadri S. Non-alcoholic fatty liver disease, liver fibrosis score and cognitive function in middleaged adults: The Framingham Study. Liver Int. 2019; 39:1713-21.

https://doi.org/10.1111/liv.14161 PMID:31155826

88. Loomba R, Sanyal AJ. The global NAFLD epidemic. Nat Rev Gastroenterol Hepatol. 2013; 10:686-90. https://doi.org/10.1038/nrgastro.2013.171 PMID:24042449

89. Vernon G, Baranova A, Younossi ZM. Systematic review: the epidemiology and natural history of nonalcoholic fatty liver disease and non-alcoholic steatohepatitis in adults. Aliment Pharmacol Ther. 2011; 34:274-85. 
https://doi.org/10.1111/j.1365-2036.2011.04724.x PMID:21623852

90. Pacana T, Fuchs M. The cardiovascular link to nonalcoholic fatty liver disease: a critical analysis. Clin Liver Dis. 2012; 16:599-613.

https://doi.org/10.1016/i.cld.2012.05.008

PMID:22824483

91. Friedman GD, Cutter GR, Donahue RP, Hughes GH, Hulley SB, Jacobs DR Jr, Liu K, Savage PJ. CARDIA: study design, recruitment, and some characteristics of the examined subjects. J Clin Epidemiol. 1988; 41:1105-16. https://doi.org/10.1016/0895-4356(88)90080-7 PMID:3204420

92. Gerber Y, VanWagner LB, Yaffe K, Terry JG, Rana JS, Reis JP, Sidney S. Non-alcoholic fatty liver disease and cognitive function in middle-aged adults: the CARDIA study. BMC Gastroenterol. 2021; 21:96.

https://doi.org/10.1186/s12876-021-01681-0 PMID:33653293

93. McGlone ER, Bloom SR. Bile acids and the metabolic syndrome. Ann Clin Biochem. 2019; 56:326-37.

https://doi.org/10.1177/0004563218817798

PMID:30453753

94. Lefebvre P, Cariou B, Lien F, Kuipers F, Staels B. Role of bile acids and bile acid receptors in metabolic regulation. Physiol Rev. 2009; 89:147-91.

https://doi.org/10.1152/physrev.00010.2008

PMID:19126757

95. Cruz-Ramón V, Chinchilla-López P, Ramírez-Pérez O, Méndez-Sánchez N. Bile Acids in Nonalcoholic Fatty Liver Disease: New Concepts and Therapeutic Advances. Ann Hepatol. 2017 (Suppl 1); 16:S58-67. https://doi.org/10.5604/01.3001.0010.5498 PMID:31196637

96. Xu JY, Li ZP, Zhang L, Ji G. Recent insights into farnesoid $X$ receptor in non-alcoholic fatty liver disease. World J Gastroenterol. 2014; 20:13493-500. https://doi.org/10.3748/wjg.v20.i37.13493 PMID:25309079

97. Sciarrillo CM, Keirns BH, Koemel NA, Anderson KL, Emerson SR. Fibroblast Growth Factor 19: Potential modulation of hepatic metabolism for the treatment of non-alcoholic fatty liver disease. Liver Int. 2021; 41:894-904.

https://doi.org/10.1111/liv.14802

PMID: 33506572

98. van den Hoek AM, Verschuren $L$, Worms $N$, van Nieuwkoop A, de Ruiter C, Attema J, Menke AL, Caspers MP, Radhakrishnan S, Salic K, Kleemann R. A Translational Mouse Model for NASH with Advanced Fibrosis and Atherosclerosis Expressing Key Pathways of Human Pathology. Cells. 2020; 9:2014.

https://doi.org/10.3390/cells9092014

PMID:32883049

99. Zuin M, Roncon L, Passaro A, Cervellati C, Zuliani G. Metabolic syndrome and the risk of late onset Alzheimer's disease: An updated review and meta-analysis. Nutr Metab Cardiovasc Dis. 2021; 31:2244-52.

https://doi.org/10.1016/j.numecd.2021.03.020

PMID:34039508

100. Varma VR, Wang Y, An Y, Varma S, Bilgel M, Doshi J, Legido-Quigley C, Delgado JC, Oommen AM, Roberts JA, Wong DF, Davatzikos C, Resnick SM, et al. Bile acid synthesis, modulation, and dementia: A metabolomic, transcriptomic, and pharmacoepidemiologic study. PLoS Med. 2021; 18:e1003615.

https://doi.org/10.1371/journal.pmed.1003615 PMID:34043628

101. Jia W, Rajani C, Kaddurah-Daouk R, Li H. Expert insights: The potential role of the gut microbiome-bile acid-brain axis in the development and progression of Alzheimer's disease and hepatic encephalopathy. Med Res Rev. 2020; 40:1496-1507.

https://doi.org/10.1002/med.21653

PMID:31808182

102. Picard C, Poirier A, Bélanger S, Labonté A, Auld D, Poirier J, and PREVENT-AD Research Group. Proprotein convertase subtilisin/kexin type 9 (PCSK9) in Alzheimer's disease: A genetic and proteomic multicohort study. PLoS One. 2019; 14:e0220254. https://doi.org/10.1371/journal.pone.0220254 PMID:31437157 